\title{
Exploring workplace diversity and organisational effectiveness: A South African exploratory case study
}

\begin{tabular}{|c|c|}
\hline \multicolumn{2}{|c|}{$\begin{array}{l}\text { J. Veli Mazibuko }{ }^{1} \\
\text { Krishna K. Govender }\end{array}$} \\
\hline $\begin{array}{l}\text { Affiliations: } \\
{ }^{1} \text { Department } \\
\text { Administratio } \\
\text { Management } \\
\text { Business Scho }\end{array}$ & $\begin{array}{l}\text { of Business } \\
n \text { and } \\
\text { Regenesys } \\
\text { ol, South Africa }\end{array}$ \\
\hline \multicolumn{2}{|c|}{$\begin{array}{l}{ }^{2} \text { School of Management, } \\
\text { IT and Governance, } \\
\text { University of KwaZulu-Natal, } \\
\text { South Africa }\end{array}$} \\
\hline \multicolumn{2}{|c|}{$\begin{array}{l}\text { Corresponding author: } \\
\text { Krishna Govender, } \\
\text { govenderkrishna@gmail.com }\end{array}$} \\
\hline \multicolumn{2}{|c|}{$\begin{array}{l}\text { Received: } 16 \text { Sept. } 2016 \\
\text { Accepted: } 12 \text { Sept. } 2017 \\
\text { Published: } 23 \text { Nov. } 2017\end{array}$} \\
\hline \multicolumn{2}{|c|}{$\begin{array}{l}\text { How to cite this article: } \\
\text { Mazibuko, J.V., \& Govender, } \\
\text { K.K. (2017). Exploring } \\
\text { workplace diversity and } \\
\text { organisational effectiveness: } \\
\text { A South African exploratory } \\
\text { case study. SA Journal of } \\
\text { Human Resource } \\
\text { Management/SA Tydskrif vir } \\
\text { Menslikehulpbronbestuur, } \\
\text { 15(0), a865. https://doi. } \\
\text { org/10.4102/sajhrm. } \\
\text { v15i0.865 }\end{array}$} \\
\hline \multicolumn{2}{|c|}{$\begin{array}{l}\text { Copyright: } \\
\text { @ 2017. The Authors. } \\
\text { Licensee: AOSIS. This wo } \\
\text { is licensed under the } \\
\text { Creative Commons } \\
\text { Attribution License. }\end{array}$} \\
\hline \multicolumn{2}{|l|}{ Read online: } \\
\hline 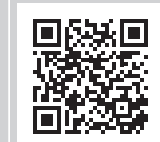 & $\begin{array}{l}\text { Scan this QR } \\
\text { code with your } \\
\text { smart phone or } \\
\text { mobile device } \\
\text { to read online. }\end{array}$ \\
\hline
\end{tabular}

Orientation: Transformation and managing diversity are organisational imperatives, especially in South Africa. Thus, it is important for international companies with major operations in South Africa (SA) to embrace the benefits of managing a divergent workforce and translate this for organisational benefits.

Research purpose: The article explores the perceptions of management and staff on diversity and its value to the organisation, by empirically evaluating the relationship with organisational effectiveness and performance through the development and testing of five hypotheses.

Motivation for the study: Legislation has made it mandatory for transformation of the South African workplace and ensuring that diversity is embraced. However, not all companies have fully understood the benefits of recruiting and managing diverse teams for the benefit of the organisation.

Research approach, design and method: Both quantitative and qualitative approaches were used, whereby a survey was conducted among 227 employees using the Towers Watson Employment Employee Insight Survey (EIS). Inferential statistical techniques were used to test relationships among related variables postulated through five hypotheses.

Main findings: It was ascertained that understanding and managing diversity has played a pivotal role in the (research) organisation's performance and effectiveness over the past 5 years. More specifically, diversity management created room for appreciation, innovation and creativity that gave the organisations an edge to tackle diverse markets.

Practical/managerial applications: South Africa has a diverse population, and when individuals join an organisation, they bring a unique set of characteristics referred to as personalities, which, through the socialisation process, get assimilated into teams' norms and values, and the culture of the organisation. Managing diversity in the workplace is part of employee retention and attraction, with the intention to energise workplace productivity, thus increasing the organisation's competitive edge.

Contributions or value add: The positive impact engendered by diverse recruitment and retention is also supported by employee engagement, which presupposes employee ownership of change, by making it happen, and it is driven by employees that offer solutions to problems, by helping one another and who are proud of being part of the organisation. Its impact in the bigger scheme of events is to drive business performance, growth, cost management, and ability to attract, retain and engage top talent by establishing a winning and inclusive culture.

\section{Introduction}

When individuals join an organisation, they bring a unique set of characteristics referred to as personalities, and through the socialisation process, they get assimilated into their teams' norms and values, and eventually, the culture of the organisation. Ferreira and Coetzee (2010) posit that managing diversity in the workplace is part of employee retention and attraction, with the intention to energise workplace productivity, thus increasing the organisation's competitive edge. The positive impact engendered by diverse recruitment and retention is also supported by employee engagement (Neault \& Mondair, 2011). Employee engagement presupposes employee ownership of change, by making it happen, and it is driven by employees that offer solutions to problems, by helping one another and who are proud of being part of the organisation. Its impact in the bigger scheme of events is to drive business performance, growth, cost management, and ability to attract, retain and engage top talent by establishing a winning and inclusive culture. 
Although there is much debate on the definition of diversity, Esty, Schorr-Hirsh and Griffin (1995), cited in Green, Lopez, Wysocki and Kepner (2002), define diversity as 'acknowledging, understanding, accepting, valuing, and celebrating differences among people with respect'. McEnrue (1993) posits that diversity management is an organisational imperative and competitive necessity that contributes to its strategic intent. Daniel (1994) argues that the lack of diversity is the businesses' downfall, and the understanding and appreciation of diversity is beyond mere compliance. It has to transcend legislation by being an organisational imperative that truly recognises the value individuals add to an organisation without being stigmatised or dubbed affirmative action appointees.

The argument for diversity is complex, and it is not just about comparing and pitting people or groups against one another, but recognition and appreciation of the uniqueness and contribution to the team and organisation. Kamps and Engelbrecht (2011) assert that discrimination as part of the political legacy in South Africa (SA) has created serious challenges for workplace diversity. If organisations could determine requirements that reinforce diversity, they are better placed to improve cohesion, interaction and team work.

Diversity is also confused with employment equity and affirmative action, although the aforementioned programmes should be viewed as 'tools' to engineer and drive diversity (Mason, Williams \& Cranner, 2009). A number of workplaces still battle to meet employment equity targets, with specific reference to gender and the disabled. It is at the core of this challenge that society and organisations must ensure that people managers leverage the untapped resources that contribute to the diverse workforces (Rogatschnig, 2011).

Although most studies focus on diversity management, there is a gap in establishing the empirical link between diversity, diversity management and organisational effectiveness that translates into business performance. Kochan et al. (2003) capture the essence of this 'gap' which raises ambiguity on whether diversity is good or bad for business. The closest body of knowledge and research that explores this link in the South African context is within the financial service sector (Carelse, 2013). The aforementioned asserted that successful implementation of diversity management brings about positive employee attitude and creates a competitive organisation. Leonard and Grobbler (2006), as cited in Booysen and Nkomo (2014), posit that implementation of Employment Equity (in SA) has been reduced to legal compliance, instead of substantial compliance, and affirmative action is perceived as reverse discrimination, thus creating resistance to the process, as well as casting doubt around affirmative action appointees with an outlook of incompetence, lack of skill, ability and qualifications (Booysen \& Nkomo, 2014).

In light of the above, this article will attempt to fill this 'void' by investigating whether an organisation that embraces diversity is more effective and whether performance is in any way impacted on by their diversity.

\section{Literature review}

The end of apartheid has brought a resurgence of research into racial identities, attitudes and behaviour in SA (Seekings, 2008), and the legacy of systematic racial ordering and discrimination under apartheid is that SA remains deeply racialised, in cultural and social terms, as well as unequal in terms of distribution of income and positions held in organisations.

South Africans have also experienced major changes in the landscape of employment relations in organisations over the past two decades (Booysen, 2007), and although numerous legislations have been put in place to achieve greater social justice, progress in redressing unfair discrimination in the workplace has been slow and uneven.

Coupled with the above challenges that define the South African workplace, managing diversity, multiculturalism, affirmative action and equal employment opportunity are words in 'common currency in a newly democratic South Africa, as they are in most democratic countries of the world' (Human, 1996).

The largest field-based research project was undertaken by Diversity Research Network under the auspices of BOLD (Business Opportunities for Leadership Diversity) (Kochan et al., 2003). BOLD recommended the promotion and development of a culture that is geared to value and appreciate diversity. There are striking similarities between the aforementioned research that was conducted in the USA with the current South African study. In SA, legislations like the Employment Equity Act of 1998, Promotion of Equality and Prevention of Unfair Discrimination Act of 2000, and Black Economic Empowerment Act of 2003 were enacted to transform workplaces and provide access to equal opportunities. The essence of the abovementioned legislations was to eliminate exclusion in the workplace, of persons based on race, gender and sex.

South Africa has experienced radical political transformation over the past 12 years that is epitomised by shifts in the dominance, status and power bases of different population groups (Booysen, 2007). This transformation has in turn resulted in identity crises with the unbundling of former social identification and socialisation to refined and redefined self-concepts. The most salient identity groups in SA are race, gender, ethnicity and language (Booysen \& Nkomo, 2014). Tensions and conflicts are prevalent between diverse groups in the South African workplace, and this is no different from the international norm; but the most pressing conflict in the South African workplace is based on changes and conflicts associated with race and gender (Booysen \& Nkomo, 2014); thus, legislations have had to be enacted to fast track transformation with a view to engender equality. 
Although some researchers (Jackson, May \& Whitney, 1995) assert that there is no verified literature that confirms that diverse groups necessarily perform better, others (Hofstede, 1994, cited by Schultz, Bagraim, Potgieter, Viegde \& Werner, 2003) have linked diversity to creative problem-solving and productivity. Moreover, Simons and Rowland (2011) argue that functional diversity and non-functional diversity are critical to diversity management, and Bunderson and Sutcliffe (2002) posit that functional diversity improves organisational effectiveness and creative thinking.

Although the Corporate Research Forum (CRF) (2011) focuses on the problem-solving aspects of diversity and the diversity paradox which argues that diversity engenders conflict, it also recognises that conflict and contradictions result in innovation and well-thought through solutions to a problem. Conflict in this instance is seen as a catalyst to debate, discussions, engagement and innovation that fosters continuous improvement and business performance. According to Tatli and Ozbilging (2012), organisational commitment to diversity is determined by a business case, and diversity management enables performance improvements. Knouse and Dansby (1999) argue that organisational diversity fosters synergy, networks and multi-tasking, and organisations that manage diversity properly are successful in the accomplishment of their objectives. Organisations are motivated by a number of factors to implement diversity management, and it is consideration of this motivation, and a shift from the bottom line to the triple bottom line, that has engendered significant in-roads and influences the way the organisation approaches diversity (Brabet, 2011; Guillaume, Dawson, Woods, Sacramento \& West, 2013; Jonsen, Tatli, Özbilgin \& Bell, 2013; Klarsfeld, Ng \& Tatli, 2012).

Research on whether diversity leads to better performance (or not) has produced contradictory results, and in some instances, no clear conclusions have been forthcoming. Some researchers (Weiliang, Mun, Chern, Fong \& Yuan, 2012) posit that organisations that embrace strong gender diversity have demonstrated superior performance, and companies with diverse teams have shown exceptional performance. However, the aforementioned researchers have also clarified that the performance depends on whether the climate in the organisation fosters trust and mutual support.

Konrad (2003) presented three primary arguments in making a business case for diversity. Firstly, organisations compete for the best talent that makes it necessary for them to cast their net wide when they recruit, hence the quest for diversity. Secondly, diversity prepares the organisation to deal with diverse markets so as to increase its market share. Thirdly, diversity becomes the foundation for creative thinking by producing various ideas, opinions and solutions to a problem, which makes the team flexible and competitive. The fact that markets are diverse, affirming and accepting differences is 'socially acceptable' by embracing diversity that reflects the markets. The aforementioned view is aligned with the CRF (2011) report that alludes to an effective way of creating an inclusive culture and valuing diversity.
Schreuder and Coetzee (2011) posit that the 21st century workplace has been evolutionary instead of revolutionary, and within the South African context, 'affirmative action (AA)' and 'employment equity (EE)' have become significant tools to address the inequalities of the past. Madihlaba's (2011) assertion of 'legal compliance versus substantive compliance' or ethical imperative necessitates attention. There is need to refocus this perception to benefit the organisation and avoid unnecessary lawsuits as a result of perceived discrimination or citation of reverse discrimination.

Muhtar Kent, President of Coca-Cola, posits that everything that is done at Coca-Cola in terms of diversity is based on the simple, powerful and global premise, namely that CocaCola's diversity should be as inclusive as the brand itself (Kent, 2012). This is aligned to the global mission, which is to mirror the diversity of the marketplace that the company serves, by being the market leaders in diversity, inclusion and fairness in every aspect of the business, from the workplace, marketplace, supplier engagement and the community. Thus, diversity at Coca-Cola is integral to how the company operates and how they perceive the future.

Ssegawa (2011) explains that Coca-Cola South Africa's talent strategy is also aligned with the Company's Vision 2020, which recognises that the world is changing very fast. CocaCola (SA's) strategy for delivering great results is built on the strong foundation of a 'total rewards' platform, which involves competitive pay, the opportunity to grow and thrive, and a work environment that promises sustainability, diversity, wellness and the observance of human rights. The Coca-Cola Code of Conduct is a set of policies, principles and values that each and every new employee gets inducted into, with continuous annual refresher training to embed the following: treat colleagues fairly, honestly and with respect; respect and promote diversity in the workplace; health and safety in the workplace; and respect for colleagues and human rights. According to Ssegawa (2011), Coca-Cola SA actively seeks to create and inspire people to be their best.

This study on which the article has been developed tracks the evolution of diversity over the past 5 years, so as to determine what is the level of diversity in the organisation and what significance (if any) does diversity hold for the organisation and its employees. More specifically, the impact of diversity on performance as posited by Guillaume et al. (2013) is investigated. Moreover, the fact that the company was dominated by white male and male in general motivated the context of the study.

Velaquez (2013) posits that diversity is loaded with all kinds of myths, misconceptions and baggage that have presented management challenges, which among others, the Coca-Cola Company is striving to address, namely different culture and history that have to be tailored to suit the conditions of the country, region and geographic location; work-life balance to suit the needs of the various employees in its employ, especially women and the previously marginalised or disadvantaged; high cost of diversity with programmes undertaken to ensure 
accommodation of the diverse workforce; and lawsuits as a result of reported discriminatory cases.

It is against the above background that this article seeks to understand the research organisation's approach to diversity, and to ascertain whether diversity is a strategic tool to enhance organisational performance. In order to explore the aforementioned, the following hypotheses were formulated with respect to the research organisation:

- Hypothesis 1 (H1): Managing and valuing diversity enhances performance.

- Hypothesis 2 (H2): Diversity influences organisational effectiveness.

- Hypothesis 3 (H3): Performance is the outcome of diversity.

- Hypothesis 4 (H4): Diversity influences and drives transformation.

- Hypothesis 5 (H5): Diversity influences organisational effectiveness that translates into performance improvement.

\section{Research methodology}

A quantitative approach was used, aimed at determining the employees' perception of diversity, its relevance to them as employees and whether it adds value to their performance. The population (539) comprised all employees of the organisation in SA, and the probability sample of 300 was randomly selected after the population was stratified on the basis of occupational level, race, gender and tenure, with only those who were more than 5 years in the organisation being included. Questionnaires were hand delivered to employees across all occupational levels, from top management or directors to semi-skilled employees who were employed in the organisation for 5 years and longer. In terms of race, the sample was dominated by Africans (239), followed by 49 white people, 7 Indians and 5 mixed race. ${ }^{1,2}$

\section{Data collection and analysis}

The survey questionnaire mirrored the Employee Insight Survey (EIS) (2014) questionnaire used by Towers Watson to determine causality between diversity, organisational effectiveness and business performance. It comprised 25 Likert scaled questions designed to determine employees' perceptions of diversity, value of diversity, belief in the goals and objectives of the organisation, pride in the organisation as the best place to work, by being enabled, energised and engaged. Diversity in this instance is the independent variable on which performance and effectiveness are dependent. A 5-point scale was used where $5=$ strongly agree, $4=$ agree, $3=$ not sure, $2=$ disagree and $1=$ strongly disagree. The questionnaire, though adapted for the South African context, is valid and reliable, because it has been consistently used in the research organisation in the past 5 years, and has yielded consistent results. The performance

1.In the South African context, black people comprise Africans, Indians and mixed race.

2.There are 56.5 million people in SA (Stats SA, 2017): $79.4 \%$ Africans, $9.2 \%$ white people, $8.8 \%$ mixed race and $2.6 \%$ Indians. results of the organisation for the last 5 years, Broad-Based Black Economic Empowerment (BBBEE) Certificates and EE reports were also analysed to establish the link between diversity in the workplace, organisational effectiveness and business performance. The equity reports that were a mandatory annual submission to the Department of Labour were also scrutinised to authenticate the complexion of the organisation, based on gender and demographics (designated groups), in alignment with the actual statistics generated from the survey. This was also supported by analysis of the BBBEE certificates to determine the level of transformation that covers a host of elements like ownership, procurement and corporate social investment, that is, matched to diversity.

The data were analysed using the SPSS programme to calculate percentages and conduct correlation and analysis of variance (ANOVA) tests.

\section{Findings}

A total of 227 questionnaires were completed and returned, comprising 82 from semi-skilled, 74 unskilled, 48 skilled, and 15 middle and 8 senior managers. There was male dominance at the unskilled staff level, whereas gender representation at other levels was more balanced. Table 1 indicates dominant response by Africans, followed by white people, which indicates that the organisation still lacks adequate Indian and mixed race representation in the workforce. Among the 173 African employees, the majority (74) were either unskilled or semi-skilled (67), and among the 42 white employees, the majority (23) were either skilled professionals or semi-skilled.

The reliability of the five dimensions in the survey were examined using the Cronbach's alpha coefficient statistics. Although only two dimensions produced alpha coefficients that exceeded 0.7 , namely knowledge sharing and the impact of diversity on organisational effectiveness, and the other individual scores ranged between 0.45 and 0.56 ; the overall reliability of the instrument was 0.85 , which according to Cronbach and Meehl (1955) is an acceptable score.

With regard to 'the value of diversity', Table 2 indicates that the majority $(60 \%)$ of the respondents 'strongly agree' that they are treated with dignity and respect. The results also confirm the respondents' appreciation of the company's recruitment of a diverse workforce. Furthermore, the vast majority $(71 \%)$ of the respondents confirm that diversity enhances innovation and productivity, and 56\% 'strongly disagree' that diversity creates confusion and conflict in the workplace.

It is evident from Table 3 that the corrected model is significant and shows that managing and valuing diversity enhances performance. The results of the ANOVA test showed that diverse workforce $[F(4.174)=13.10, p<0.001]$, individual differences $[F(4.174)=7.16, p<0.001]$ and confusion conflict $[F(4.174)=5.52, p<0.001]$ are significantly related with 
TABLE 1: Racial profile of respondents by occupational level.

\begin{tabular}{|c|c|c|c|c|c|}
\hline \multirow[t]{2}{*}{ Occupational level } & \multicolumn{4}{|c|}{ Racial group } & \multirow[t]{2}{*}{ Total } \\
\hline & Africans & Mixed race & Indian & White people & \\
\hline Top management & 0 & 0 & 0 & 0 & 0 \\
\hline Senior management & 4 & 0 & 1 & 3 & 8 \\
\hline Middle management & 9 & 1 & 1 & 4 & 15 \\
\hline Skilled professionals & 19 & 4 & 2 & 23 & 48 \\
\hline Semi-skilled & 67 & 0 & 3 & 12 & 82 \\
\hline Unskilled & 74 & 0 & 0 & 0 & 74 \\
\hline Total & 173 & 5 & 7 & 42 & 227 \\
\hline
\end{tabular}

TABLE 2: Employee's perceptions of the value of diversity.

\begin{tabular}{|c|c|c|c|c|c|}
\hline Question & SD & DS & Do not know & AS & SA \\
\hline I am treated with dignity and respect at work & 27 & 12 & 31 & 20 & 137 \\
\hline $\begin{array}{l}\text { The company recruits employees from all walks of life and has a } \\
\text { diverse workforce }\end{array}$ & 25 & 5 & 20 & 9 & 168 \\
\hline $\begin{array}{l}\text { Individual differences are valued and appreciated by the } \\
\text { organisation }\end{array}$ & 37 & 9 & 29 & 5 & 147 \\
\hline $\begin{array}{l}\text { A diverse workforce creates confusion and conflict in the } \\
\text { workplace }\end{array}$ & 126 & 20 & 18 & 11 & 52 \\
\hline $\begin{array}{l}\text { A diverse workforce creates innovation and workplace } \\
\text { productivity }\end{array}$ & 18 & 8 & 23 & 17 & 161 \\
\hline
\end{tabular}

SD, strongly disagree; DS, disagree somewhat; AS, agree somewhat; SA, strongly agree.

TABLE 3: Statistical results on diverse workforce, innovation and productivity.

\begin{tabular}{|c|c|c|c|c|c|}
\hline Source & Type III sum of squares & $d f$ & Mean square & $F$ & Sig. \\
\hline Corrected model & $307.45^{\mathrm{a}}$ & 52 & 5.91 & 20.50 & 0.00 \\
\hline Intercept & 552.01 & 1 & 552.01 & 1914.10 & 0.00 \\
\hline Dignity respect & 0.97 & 4 & 0.24 & 0.84 & 0.50 \\
\hline Diverse workforce & 15.11 & 4 & 3.78 & 13.10 & $0.00 *$ \\
\hline Individual differences & 8.26 & 4 & 2.06 & 7.16 & $0.00 *$ \\
\hline Confusion conflict & 6.37 & 4 & 1.59 & 5.52 & $0.00 *$ \\
\hline Dignity respect * diverse workforce & 0.00 & 0 & - & - & - \\
\hline Dignity respect $*$ individual differences & 0.45 & 6 & 0.08 & 0.26 & 0.95 \\
\hline Dignity respect * confusion conflict & 0.67 & 3 & 0.22 & 0.77 & 0.51 \\
\hline Diverse workforce $*$ individual differences & 0.00 & 0 & - & - & - \\
\hline Diverse workforce * confusion conflict & 0.11 & 2 & 0.05 & 0.18 & 0.83 \\
\hline Individual differences * confusion conflict & 0.26 & 1 & 0.26 & 0.89 & 0.35 \\
\hline Dignity respect $*$ diverse workforce * individual differences & 0.00 & 0 & - & - & - \\
\hline Dignity respect $*$ diverse workforce $*$ confusion conflict & 0.00 & 0 & - & - & - \\
\hline Dignity respect * individual differences * confusion conflict & 0.00 & 0 & - & - & - \\
\hline Diverse workforce * individual differences * confusion conflict & 0.00 & 0 & - & - & - \\
\hline $\begin{array}{l}\text { Dignity respect * diverse workforce * individual differences * } \\
\text { confusion conflict }\end{array}$ & 0.00 & 0 & - & - & - \\
\hline Error & 50.18 & 174 & 0.29 & - & - \\
\hline Total & 4554.00 & 227 & - & - & - \\
\hline Corrected total & 357.63 & 226 & - & - & - \\
\hline
\end{tabular}

a, $R$ squared $=0.86$ (Adjusted $R$ squared $=0.82$ ).

$*$, Significant at level of significance of 0.05 .

performance in terms of innovation and workplace productivity. These were the only $p$-values less than the level of significance of 0.05 ; thus, $\mathrm{H} 1$ is supported.

Table 4 reflects that the corrected model is not significant, which implies that diversity in terms of success attributes diversity $[F(4.174)=0.20, p=0.94]$, innovative solution $[F(4.174)=1.35, p=0.25]$ and diverse customer need $[F(4.174)=0.43, p=0.79]$ is not related with the performance of an organisation in terms of the organisation's strategic priorities. The reason for this conclusion is because the $p$-values were greater than the level of significance of 0.05 . Based on the aforementioned, H2 is not supported by the findings of this study.
According to Table 5, the corrected model is significant, which implies that leadership diversity strongly influences organisational performance and/or effectiveness. Specifically, the results of the ANOVA test show that diverse programmes $[F(4.174)=11.33, p<0.001]$ and sexism or discrimination $[F(4.174)=2.61, p=0.04]$ are significantly related with performance in terms of 'proud to be part of their organisation and recommend it as the best place to work'. All the $p$-values were less than the level of significance of 0.05 . Hence, it may be concluded that $\mathrm{H} 3$ is supported in this study.

Table 6, which represents the influence of diversity on transformation, indicates that $75 \%$ of the respondents 'strongly agree' that AA is a positive measure that supports 
TABLE 4: The influence of diversity on organisational effectiveness.

\begin{tabular}{|c|c|c|c|c|c|}
\hline Source & Type III sum of squares & $d f$ & Mean square & $\boldsymbol{F}$ & Sig. \\
\hline Corrected model & $140.03^{\mathrm{a}}$ & 25 & 5.60 & 3.85 & 0.00 \\
\hline Intercept & 431.91 & 1 & 431.91 & 296.47 & 0.00 \\
\hline Success attribute diversity & 1.17 & 4 & 0.29 & 0.20 & 0.94 \\
\hline Innovative solution & 7.85 & 4 & 1.96 & 1.35 & 0.25 \\
\hline Diverse customer need & 2.50 & 4 & 0.62 & 0.43 & 0.79 \\
\hline Success attribute diversity * innovative solution & 15.01 & 2 & 7.50 & 5.15 & 0.01 \\
\hline Success attribute diversity $*$ diverse customer need & 2.98 & 1 & 2.98 & 2.04 & 0.15 \\
\hline Innovative solution * diverse customer need & 1.14 & 1 & 1.14 & 0.78 & 0.38 \\
\hline $\begin{array}{l}\text { Success attribute diversity * innovative solution * Diverse } \\
\text { customer need }\end{array}$ & 0.00 & 0 & - & - & - \\
\hline Error & 292.82 & 201 & 1.46 & - & - \\
\hline Total & 4417.00 & 227 & - & - & - \\
\hline Corrected total & 432.86 & 226 & - & - & - \\
\hline
\end{tabular}

a, $R$ squared $=0.32$ (Adjusted $R$ squared $=0.24$ ).

TABLE 5: The influence of leadership diversity on performance and effectiveness.

\begin{tabular}{|c|c|c|c|c|c|}
\hline Source & Type III sum of squares & $d f$ & Mean square & $F$ & Sig. \\
\hline Corrected model & $68.94^{\mathrm{a}}$ & 14 & 4.92 & 4.89 & 0.00 \\
\hline Intercept & 619.80 & 1 & 619.80 & 614.94 & 0.00 \\
\hline Diversity programmes & 45.67 & 4 & 11.42 & 11.33 & $0.00 *$ \\
\hline Sexism or discrimination & 10.51 & 4 & 2.63 & 2.61 & $0.04 *$ \\
\hline $\begin{array}{l}\text { Diversity programmes * } \\
\text { sexism or discrimination }\end{array}$ & 13.30 & 6 & 2.22 & 2.20 & 0.04 \\
\hline Error & 213.68 & 212 & 1.01 & - & - \\
\hline Total & 4830.00 & 227 & - & - & - \\
\hline Corrected total & 282.62 & 226 & - & - & - \\
\hline
\end{tabular}

Dependent variable: 17 . I am proud to be part of my organisation and recommend it as the best place to work.

a, $R$ squared $=0.24$ (Adjusted $R$ squared $=0.19$ ).

*, Significant at level of significance of 0.05 .

TABLE 6: Influence of diversity on transformation.

\begin{tabular}{|c|c|c|c|c|c|}
\hline Question & SD & DS & Do not know & AS & SA \\
\hline Affirmative action is a positive measure to support diversity in the company & 29 & 8 & 12 & 8 & 170 \\
\hline Affirmative action is reverse discrimination & 102 & 1 & 21 & 6 & 97 \\
\hline The company is gender balanced and supports women leadership at work & 21 & 7 & 14 & 23 & 162 \\
\hline Employment equity is good and ethical, and my company is beyond compliance & 21 & 6 & 42 & 11 & 147 \\
\hline The company supports transformation and is compliant & 25 & 8 & 40 & 7 & 144 \\
\hline
\end{tabular}

SD, strongly disagree; DS, disagree somewhat; $A S$, agree somewhat; $S A$, strongly agree.

diversity. AA as reverse discrimination is not differentiated by respondents who strongly agree and strongly disagree and is almost balanced at $43 \%$ and $45 \%$, respectively. The vast majority $(71 \%)$ of the respondents 'strongly agree' that the company is gender balanced and supports women leadership at work. The confirmation of AA as a positive measure in line with gender balance, transformation and equity supports the dominant view in the organisation on the influence diversity plays in transformation.

Table 7, which represents the univariate statistical analysis for determining the influence of diversity in driving transformation, reveals that the corrected model is significant, which shows that diversity influences and drives transformation. Specifically, the results of the ANOVA test showed that AA positive $[F(4.174)=7.83$, $p<0.001]$, AA discrimination $[F(3.174)=23.15, p<0.001]$ and women leadership $[F(4.174)=4.07, p<0.001]$ are significantly related with driving transformation. The $p$-values were less than the level of significance of 0.05 . Given the above, H4 is supported, and it is concluded that diversity influences transformation.
With respect to the drivers of organisational outcomes that determine the relationship between diversity, organisational effectiveness and performance, it became evident that $84 \%$ of the respondents are in favour of the promotion of diversity as the key driver of organisational outcomes. The majority (62\%) of the male respondents are in support of promoting diversity, compared with $37 \%$ of the female respondents. The vast majority $(76 \%)$ of the African employees' respondents supported the view that diversity is a motivational aspect of performance.

Table 8 reflects that promoting diversity is significantly related with performance improvement in terms of knowledge to drive transformation $\left[X^{2}(1)=13.10, p<0.001\right]$, increased previously disadvantaged individuals (PDIs) at senior management level $\left[X^{2}(1)=37.35, p<0.001\right]$, and cultural diversity and gender sensitive $\left[X^{2}(1)=19.34, p<0.001\right]$. It is therefore concluded that there is a relationship between diversity and organisational effectiveness, which translates into performance improvement; thus, H5 is supported.

It was also ascertained that $64 \%$ of the respondents 'strongly agreed' that the organisation allows for knowledge sharing 
TABLE 7: Statistical test results for diversity influence on transformation.

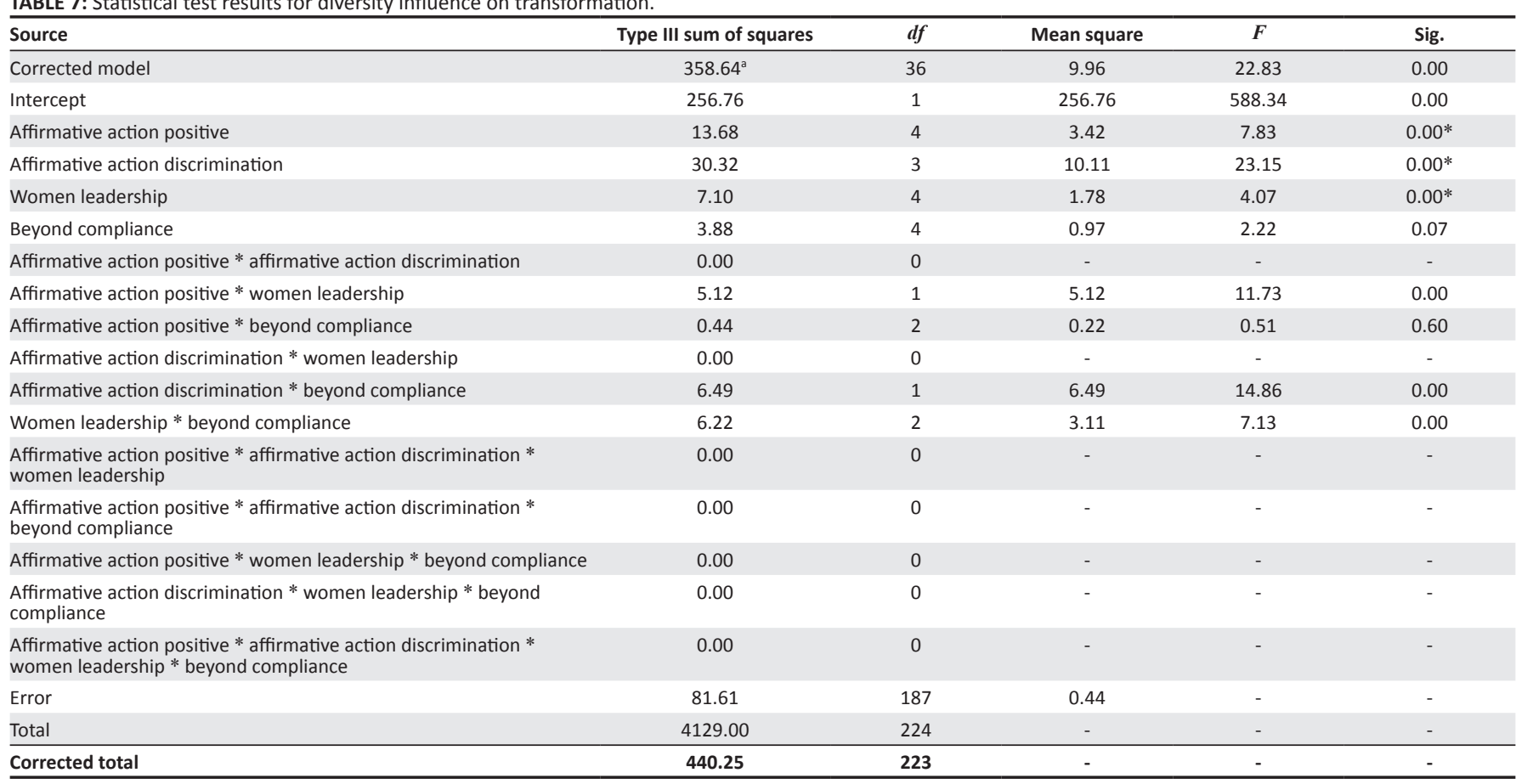

Dependent variable: 10 . The company supports transformation and is compliant.

a, $R$ squared $=0.82$ (Adjusted $R$ squared $=0.78$ ).

$*$, Significant at level of significance of 0.05 .

TABLE 8: The relationship between diversity, organisational effectiveness and business performance.

\begin{tabular}{|c|c|c|c|}
\hline Independent variable & Value & $d f$ & Asymp. Sig. (two-sided) \\
\hline Developing skills & 2.62 & 1 & 0.11 \\
\hline Knowledge to drive transformation & 10.47 & 1 & $0.00 *$ \\
\hline $\begin{array}{l}\text { Increased PDI's at senior } \\
\text { management level }\end{array}$ & 37.35 & 1 & $0.00 *$ \\
\hline $\begin{array}{l}\text { Cultural diversity and gender } \\
\text { sensitive }\end{array}$ & 19.34 & 1 & $0.00 *$ \\
\hline $\begin{array}{l}\text { Increased emphasis to legislative } \\
\text { compliance }\end{array}$ & 1.17 & 1 & 0.28 \\
\hline
\end{tabular}

Dependent variable: 1 . Promoting diversity.

PDI, previously disadvantaged individuals.

*, Significant at level of significance of 0.05 .

among employees; the vast majority $(71 \%)$ of the respondents 'strongly agreed' that they share knowledge and views with their peers.

\section{Discussion of the findings}

It is evident that with respect to the research organisation, managing and valuing diversity enhances performance, which findings are in line with Roberge, Lewicki, Heitapelto and Abdyldaeva (2011) and Carelse (2013). The policies, procedures, systems and values that include teamwork are among the initiatives that received emphasis in the organisation, clearly demonstrating employee awareness of the importance of diversity. The aforementioned finding is similar to Bulbulia's (2003:n.p.) argument that the goal of managing diversity should be to maximise employee potential unhindered by group identities by ensuring a conducive workplace where similarities and differences are appreciated'. Ely and Thomas (2001) suggest that depending on the work group's diversity perspective, members of culturally diverse groups can relate to each other, such that the members feel valued and respected and this has been the key in the research organisation. Rosado (2006) argues in favour of total quality diversity as a holistic diversity management programme that assures unity in diversity, and the research organisation truly represents this.

Although Page (2011) argues in favour of diversity and different levels of experience for performance improvement, he also pointed out that diversity in terms of 'success attribute', innovative solutions and diverse customer need is not related with the productivity of an organisation. In line with the aforementioned, Kochan et al. (2003) posited that diversity does not necessarily engender productivity. The results of this study therefore confirm the mixed results presented by Bowers, Pharmer and Salas (2000) and Webber and Donahue (2001), namely, that diversity does not necessarily improve performance, and it points to the socalled double-edged sword effect of diversity (Milliken \& Martins, 1996).

Although it became evident that the success of the (research) organisation in the last 5 years can be ascribed to diversity with innovative solutions, it is, however, important to note that the 'innovative solution' is linked to aspects like capability building through the Competency Acquisition and Management Development programmes. The results are similar to Horwitz and Horwitz's (2007) findings that positive teams' impact performance on task-related diversity versus bio-demographic diversity.

In line with previous studies (Chin, 2013), it was ascertained that leadership diversity strongly influences organisational performance and/or effectiveness. The leadership role is 
assumed to clear up the ambiguity of contrasting theories on whether diversity influences performance, which performance in turn results in the realisation of strategic organisational objectives. Ssegawa (2011:n.p.) posits that the organisation must 'get ready for tomorrow today' by attracting, developing and engaging highly talented and diverse workforce to drive cross-pollination of innovative ideas, and this was evident in the organisation where this study was conducted.

The findings in this study are consistent with what is reflected in the BBBEE certification of the research organisation, which reflect its ratings as rising from level 4 in 2010 to level 2 at the time of research. This reflects not just management evolution, but shareholder engagement of 'Broad-Based' partners that control 70\% of the shareholding, and $5 \%$ ownership by employees on Share Appreciation Rights Scheme. The impact of this transformation is reflected in initiatives which the organisation undertook to involve women entrepreneurs and the footprint it established in its corporate social investment in ensuring that it achieves more than the triple bottom line. Swanepoel, Erasmus and Schenk (2008) argue that the platform set by the BBBEE Act challenges organisations to empower more and more black people through affirmative action. With respect to the research organisation, women were recruited or promoted into leadership roles beyond the $25 \%$ compliance through focused recruitment.

Ferreira and Coetzee (2010) posit that managing diversity in the workplace is part of employee retention and attraction with the intention to energise workplace productivity, thus increasing the organisation's competitive edge. It was determined that in the last 3 years, the research organisation showed growth in production volume from 38 to 45 million cases, which at some stage in 2010 was at a staggering 20 million cases per annum. The aforementioned achievement is supposedly linked to the diverse talent and innovation in the organisation because DeVeale and Manea (2007) assert that a diverse workforce leverages on the differences among the teams by strengthening their communication networks and eliminating the barriers that hinder their creative function.

With respect to employee engagement, the survey revealed a change from $52 \%$ to $84 \%$ in 2015 , indicating increased employee commitment and participation. The fact that innovation is encouraged among team members and different opinions are openly discussed creates a platform to innovate through debate and discussions, so as to find well-thought through solutions to problems. This is key to effectiveness and performance that are linked to individual capacity to perform, spanning through to the team/department and organisation performance.

\section{Conclusion and recommendations}

The conclusions with respect to the decisions on the hypotheses are summarised in Table 9.

From the findings reported above as well as the summary decisions on the hypotheses, it may be concluded that organisations in SA are challenged by the legacy of apartheid that still subtly divide organisations through 'covert' racism, prejudice and stereotyping. Hence, there is need to acknowledge, understand, accept, value and celebrate differences among people as part of the organisational policy. Diversity awareness training programmes should form part of the organisation's induction, so as to ensure that dignity, respect and valuing differences are understood by all employees and form part of the organisation's DNA.

It is management's responsibility to attract, retain and engage talent by establishing a winning and inclusive culture. Commitment to diversity promotes the right behaviour that employees will emulate, thus mitigating the negative impact diversity would have in the workplace. Organisational diversity training and development programmes must engender a culture that creates smooth assimilation of employees. Line managers should be trained in team development and conflict management to reinforce an inclusive culture that the organisation enshrines, so as to extract maximum benefit from diverse teams.

For organisations that are market driven, their strategy to serve the customer should mirror the diverse markets the company serves. An effective diversity management programme should not happen by default but by design, with clearly set objectives that do not look at transformation as 'compliance' but as an organisational imperative and an integral part of its policy and procedures.

Because employee engagement engenders participation and involvement that translates into effectiveness, there is need to constantly 'test the organisational temperature' as part of the key performance indicator of the organisation's health. It is recommended that engagement forms part of the organisational, functional and team performance metrics and key performance indicators.

TABLE 9: Decisions on the hypotheses and conclusions.

\begin{tabular}{|c|c|c|}
\hline Hypotheses & Decision & Conclusion \\
\hline $\begin{array}{l}\text { H1: Managing and valuing diversity enhances } \\
\text { performance. }\end{array}$ & Accepted & Managing and valuing diversity enhances performance. \\
\hline H2: Diversity influences organisational effectiveness. & Rejected & $\begin{array}{l}\text { Diversity in terms of success attribute diversity, innovative solution, and diverse customer need are } \\
\text { not related with the performance of an organisation in terms of the organisation's strategic priorities. }\end{array}$ \\
\hline H3: Performance is the outcome of diversity. & Accepted & Leadership diversity strongly influences organisational performance and/or effectiveness. \\
\hline H4: Diversity influences and drives transformation. & Accepted & Diversity influences and drives transformation. \\
\hline $\begin{array}{l}\text { H5: Diversity influences organisational effectiveness } \\
\text { which translates into performance improvement. }\end{array}$ & Accepted & $\begin{array}{l}\text { Promoting diversity is significantly related with performance improvement in terms of knowledge to } \\
\text { drive transformation. }\end{array}$ \\
\hline
\end{tabular}




\section{Limitations of the study and future research}

The study was limited to only one Fast Moving Consumer Goods (FMCG) company in SA. Future research could be conducted in other multi-nationals with critical mass in SA, so as to be able to compare the findings and determine success stories. The racial composition of the sample (minority Indian and mixed race participants) may not have been truly representative of the South African rainbow nation. Thus, a more diverse organisation study would be beneficial.

The causal link between diversity, engagement, effectiveness and performance should be explored using inferential statistical techniques. Because diversity management energises workplace productivity and increases the company's competitive edge, it would be critical to determine whether workplace diversity and employee engagement produce similar results. It would also be important to investigate the link between engagement, diversity, effectiveness and performance, in lieu of the fact that it commits employees by fostering growth for both the individual and the organisation.

\section{Acknowledgements Competing interests}

The authors declare that they have no financial or personal relationships that may have inappropriately influenced them in writing this article.

\section{Authors' contributions}

J.V.M. conducted the research towards his MBA dissertation, under guidance of K.K.G. The article was developed and written entirely by K.K.G.

\section{References}

Booysen, L.A.E. (2007). Societal power shifts and changing social identities in South Africa: Workplace implications for management. South African Journal of Economics and Management Sciences, 10(1), 1-20. https://doi.org/10.4102/ sajems.v10i1.533

Booysen, L.A.E., \& Nkomo, S.M. (2014). New developments in employment equity and diversity management in South Africa. In L.A.E. Booysen, A. Klarsfeld, E. Ng, and A. Tatli (Eds.), International handbook on diversity management at work: Country perspectives on diversity and equal treatment, Vol. 2 (pp. 131-182). Cheltenham Edward Elgar Publishing.

Bowers, C.A., Pharmer, J.A., \& Salas, E. (2000). When member homogeneity is needed in work teams: A meta-analysis. Small Group Research, 31, 305-327. https://doi. org/10.1177/104649640003100303

Brabet, J. (2011). Corporate social responsibility and its models in a contested field. Responsible Organization Review (ROR) 6(2), 38-50. https://doi.org/10.3917/ ror.062.0038

Bulbulia, S. (2003). Diversity: Too hot to handle. Retrieved November 29, 2015, from http://www.biz-communication.com/Article/196/18/2501.html

Bunderson, J.S., \& Sutcliffe, K.M. (2002). Comparing alternative conceptualizations of functional diversity in management teams. The Academy of Management Journal, 45(5), 875-893. https://doi.org/10.2307/3069319

Carelse, K. (2013). Employee perceptions towards workplace diversity in a financial institution operating in the Western Cape. Faculty of Economics and Management Sciences, University of Western Cape, Cape Town.

Chin, J.L. (2013). Diversity leadership: Influence of ethnicity, gender and minority status. Open Journal of Leadership, 2, 1-10. https://doi.org/10.4236/ ojl.2013.21001

Corporate Research Forum Report. (2011). Diversity and business performance Retrieved November 30, 2015, from http://www.crforum.co.uk/research-andresources/diversity-and-business-performance-2

Cronbach, L.J., \& Meehl, P.E. (1955). Construct validity on psychological test. Psychological Bulletin, 52, 281-302. https://doi.org/10.1037/h0040957
Daniel, C. (1994). How societies change. Thousand Oaks, CA: Pine Forge.

DeVeale, C., \& Manea, L. (2007). Companies embrace power of diversity. Canadian HR Reporter, 20(22), 14-15.

Ely, R., \& Thomas, D.A. (2001). Making differences matter: A new paradigm for managing diversity. Administrative Science Quarterly, 46(2), 229-273. https://doi. org/10.2307/2667087

Employee Insight Survey (EIS). (2014). Diversity councils and business resource groups. Retrieved September 23, 2015, from http://www.cocacolacompany.com/our-company/diversity/diversity-councils-andbusinesscolacompany.com
resource-groups

Ferreira, N., \& Coetzee, M. (2010). Psychological career resources and organisational commitment: Exploring socio-demographic differences. South African Journal of Labour Relations, 34(2), 25-41.

Green, K.A., Lopez, M., Wysocki, A., \& Kepner, K. (2002). Diversity in the workplace: Benefits, challenges, and the required managerial tools. Gainesville, FL: Department of Food and Resource Economics, Institute of Food and Agricultural Sciences, University of Florida. Retrieved November 29, 2015, from http://edis. ifas.ufl.edu

Guillaume, Y.R., Dawson, J.F., Woods, S.A., Sacramento, C.A., \& West, M.A. (2013). Getting diversity at work to work: What we know and what we still don't know. Journal of Occupational and Organizational Psychology, 86(2), 123-141. https:// doi.org/10.1111/joop.12009

Horwitz, S., \& Horwitz, I. (2007). The effects of team diversity on team outcomes: A meta-analytic review of team demography. Journal of Management, 33(6), 9871015. https://doi.org/10.1177/0149206307308587

Human, L. (1996). Managing workforce diversity: A critique and example from South Africa. International Journal of Manpower, 17(4/5), 46-64. https://doi. org/10.1108/01437729610127659

Jackson, S.E., May, K.A. \& Whitney, K. (1995). Dynamics of diversity in decision making teams. In R.A. Guzzo \& E. Salas (Eds.), Team effectiveness and decision making in organizations, (pp. 89-131). San Francisco, CA: Jossey-Bass.

Jonsen, K., Tatli, A., Özbilgin, M.F., \& Bell, M.P. (2013). The tragedy of the uncommons: Reframing workforce diversity. Human Relations, 66(2), 271-294. https://doi. org/10.1177/0018726712466575

Kamps, J.M., \& Engelbrecht, A.S. (2011). The influence of emotional intelligence on diversity complexity cognition and the attitude towards diversity. South African Journal Business Management, 42(3), 37-48.

Kent, M. (2012). Diversity: The Coca-Cola Company. Retrieved September 23, 2015, from http://www.coca-colacompany.com/our-company/diversity

Klarsfeld, A., Ng, E., \& Tatli, A. (2012). Social regulation and diversity management: A comparative study of France, Canada and the UK. European Journal of Industrial Relations, 18(4), 309-327. https://doi.org/10.1177/0959680112461091

Knouse, B.S., \& Dansby, R.M. (1999). Percentage of work-group diversity and workgroup effectiveness. Journal of Psychology, 133(5), 486-494. https://doi.org/ 10.1080/00223989909599757

Kochan, T., Bezrukova, K., Ely, R., Jackson, S., Joshi, A., Jehn, K., et al., (2003). The effects of diversity on business performance: Report of the Diversity Research Network. Human Resource Management, 42(1), 3-21. https://doi.org/10.1002/ hrm.10061

Konrad, A. (2003). Defining the domain of workplace diversity scholarship. Group and Organization Management, 28(1), 4-17. https://doi.org/10.1177/10596011022 50013

Madihlaba, J. (2011). Variables influencing management of diversity in the South African Public Sector. Johannesburg: University of Johannesburg.

Mason, G., Williams, G., \& Cranmer, S. (2009). Employability skills initiatives in higher education: What effects do they have on graduate Labour market outcomes? Education Economics, 17(1), 1-30. https://doi.org/10.1080/ 09645290802028315

McEnrue, M.P. (1993). Managing diversity: Los Angeles before and after the riots. Organizational Dynamics, 21(3), 18-29. https://doi.org/10.1016/0090-2616 (93)90068-C

Milliken, F.J., \& Martins, L.L. (1996). Searching for common threads: Understanding the multiple effects of diversity in organizational groups. The Academy of Management Review, 21(2), 102-133.

Neault, R.A., \& Mondair, S. (2011). Supporting workplace diversity: Emerging roles for employment counsellors. Journal of Employment and Counselling, 48(1), 72-80. https://doi.org/10.1002/j.2161-1920.2011.tb00116.x

Page, S.E. (2011). Diversity and complexity. Princeton, NJ: Princeton University Press.

Roberge, M., Lewicki, R., Heitapelto, A., \& Abdyldaeva, A. (2011). From theory to practice: Recommending supportive diversity practices. Journal of Diversity Management, 6(1), 1-20. https://doi.org/10.19030/jdm.v6i2.5481

Rogatschnig, M. (2011). Debunking diversity management. Challenges go beyond narrow definitions. Cape Town: Connemara.

Rosado, C. (2006). What do we mean by 'Managing Diversity'? Hyderabad, India: ICAFAI University.

Schreuder, A., \& Coetzee, M. (2011). Careers: An organisational perspective. Claremont: Juta and Co. Ltd. 
Seekings, J. (2008). The continuing salience of race: Discrimination and diversity in South Africa. Journal of Contemporary African Studies, 26(1), 1-25. https://doi. org/10.1080/02589000701782612

Schultz, H., Bagraim, J., Potgieter, T., Viegde, C., \& Werner, A. (2003). Organisational behavior. Pretoria: Van Schaik.

Simons, S.M., \& Rowland, K.N. (2011). Diversity and its impact on organizational performance: The influence of diversity constructions on expectations and outcomes. Journal of Technology Management and Innovation, 6(3), 172-174. https://doi.org/10.4067/S0718-27242011000300013

Ssegawa, D. (2011). Workplace culture. Retrieved July 15, 2013, from http://www. coca-colacompany.com/our-company/diversity/workplace-culture

Swanepoel, B.J., Erasmus, B.J., \& Schenk, H.W. (2008). South African human resources management. Theory and Practice. Cape Town: Juta and Co. Ltd.
Tatli, A., \& Özbilgin, M.F. (2012). An emic approach to intersectional study of diversity at work: A Bourdieuan framing. International Journal of Management Reviews, 14(2), 180-200. https://doi.org/10.1111/j.1468-2370.2011.00326.x

Velaquez, M. (2013). The Coca-Cola series. Retrieved September 25, 2015, from http://www.diversitydtg.com/article/best-practices-inclusive-strategies/thecoca-colaseries-three-articles

Webber, S.S., \& Donahue, L.M. (2001). Impact of highly and less job-related diversity on work group cohesion and performance: A meta-analysis. Journal of Management, 27(2), 141-162. https://doi.org/10.1177/ Journal of Managem

Weiliang, E.C., Mun, L.K., Chern, T.S., Fong, T.S., \& Yuan, Y.P. (2012). The effects of workforce diversity towards the employee's performance in an organization. Faculty of Business and Finance. Malaysia: University Tunku. 